\title{
A UTILIZAÇ̃̃o DA LOUSA MÁGICA NA COMUNICAÇÃO DO TRAQUEOSTOMIZADO
}

\author{
Adriana Meneghini Melles* \\ Márcia Maria Fontão Zago**
}

MELLES, A.M.; ZAGO, M.M.F. A utilização da lousa mágica na comunicação do traqueostomizado. Rev.latinoam.enfermagem, Ribeirão Preto, v. 9, n. 1, p. 73-79, janeiro 2001.

Com a finalidade de favorecer a comunicação do traqueostomizado, este estudo foi desenvolvido com o objetivo de avaliar a adequação e a aceitação da lousa mágica como recurso para a comunicação do paciente. A lousa foi fornecida a 15 traqueostomizados no $2^{\circ}$ dia pós-operatório e no $5^{\circ}$ dia foi aplicado um instrumento focalizando os objetivos. Os resultados mostram que $73 \%$ dos pacientes consideram o recurso adequado para as suas condições, $86 \%$ consideram que ela favoreceu a comunicação com a equipe de saúde e foi aceito por $96 \%$ dos pacientes. Os resultados destacam a importância de os enfermeiros buscarem recursos criativos e de baixo custo para favorecer a comunicação dos pacientes.

UNITERMOS: enfermagem, comunicação, traqueostomia

\section{INTRODUÇÃO}

$\boldsymbol{D}_{\text {e modo geral, todo procedimento cirúrgico }}$ acarreta uma série de mudanças na qualidade de vida do paciente, algumas vezes permanentes e em outras, temporárias. Além dos medos que o paciente desenvolve frente à confirmação da necessidade de submeter-se a um procedimento cirúrgico, a impossibilidade da comunicação verbal oral no pós-operatório é um aspecto que, sem dúvida nenhuma, aumenta a intensidade do estresse cirúrgico.

Para os enfermeiros, a comunicação com o paciente é considerada como um processo fundamental não apenas para a identificação de sinais, sintomas e problemas físicos mas também para o desenvolvimento da "comunicação terapêutica", a qual demonstra o comprometimento do profissional para com o paciente ${ }^{5,6}$.

A impossibilidade da comunicação verbal oral pelo paciente dificulta o seu relacionamento com a equipe de saúde. Assim, as dificuldades do paciente em informar ou relatar suas condições podem gerar a identificação de problemas equivocados pela equipe de saúde e, conseqüentemente, as ações desenvolvidas não alcançarão o resultado esperado ${ }^{6}$.
Em algumas situações cirúrgicas, a afonia (impossibilidade do uso do som laríngeo, ou seja, da voz) é uma conseqüência que dificulta a comunicação equipe de saúde/paciente. Na nossa experiência, esta é uma situação difícil para todos os envolvidos, que acarreta ansiedade irritação e frustação tanto para o paciente como para os profissionais de saúde ${ }^{2,3}$.

Entre as situações cirúrgicas acima, destacamos as cirurgias de cabeça e pescoço, principalmente as laringectomias, devido a realização da traqueostomia. As laringectomias são realizadas para a remoção total ou parcial da laringe comprometida pelo câncer. $\mathrm{Na}$ laringectomia total, a traqueostomia é definitiva e como há a remoção da laringe, o paciente apresenta afasia (perda da capacidade do som laríngeo). Na laringectomia parcial, a traqueostomia é temporária permanecendo de 7 a 30 dias. Estas são as condutas médico - cirúrgicas da equipe que atua em um hospital universitário, no qual este estudo foi realizado.

Como participantes do Grupo de Apoio e Reabilitação de Pessoas Ostomizadas: GARPO Laringectomizados, temos convivido com as dificuldades dos pacientes e dos profissionais de saúde de tentarem manter uma comunicação mas que, na maioria das vezes, é ineficiente.

Em livros textos e artigos da área de enfermagem

\footnotetext{
* Aluna do Curso de Graduação em Enfermagem. Escola de Enfermagem de Ribeirão Preto da Universidade de São Paulo. Participante do Grupo de Apoio e Reabilitação da Pessoa Ostomizada - GARPO - Laringectomizados. Bolsista PIBIC/USP/ CNPq, 1997-1998

** Professor Doutor do Departamento de Enfermagem Geral e Especializada da Escola de Enfermagem de Ribeirão Preto da Universidade de São Paulo. Coordenadora do GARPO - Laringectomizados. Orientadora do estudo. Endereço: Av. Bandeirantes, 3900 - Monte Alegre - 14040-902 - Ribeirão Preto - São Paulo - Brasil. E-mail: mmfzago@glete.eerp.usp.br
} 
em cabeça e pescoço, os autores recomendam a utilização da lousa mágica como um recurso útil, nesta situação.

Assim, este estudo foi elaborado com os objetivos de "avaliar a adequação e a aceitação da lousa mágica como recurso para a comunicação verbal escrita do paciente traqueostomizado".

\subsection{O processo de comunicação}

STEFANELLI ${ }^{6}$ define comunicação como sendo "um processo de compreender, compartilhar mensagens enviadas e recebidas, sendo que as próprias mensagens e o modo como se dá seu intercâmbio exercem influência no comportamento das pessoas nele envolvidas..." (p.30).

SILVA $^{5}$ afirma que para definir o plano de cuidados a um paciente ele precisa primeiro decodificar, decifrar e perceber o significado das mensagens que o paciente envia. É com uma comunicação efetiva que o profissional poderá ajudar o paciente a identificar suas necessidades, visualizar sua participação na experiência e participar na seleção das alternativas de solução das mesmas. Para a autora, os tipos de comunicação são: - a comunicação verbal: refere-se às palavras expressadas por meio da fala ou escrita;

- a comunicação não-verbal: refere-se aos gestos, silêncio, expressões faciais, postura corporal e outros.

STEFANELLI ${ }^{6}$ considera que a comunicação é um instrumento básico da assistência de enfermagem, ou seja, o processo que possibilita o relacionamento enfermeira-paciente, além de ser uma necessidade humana básica, que torna a existência humana possível. Para a autora, a comunicação verbal depende da linguagem, pois ela é o recurso que os pacientes utilizam para expor suas idéias e compartilhar experiências.

Para a enfermagem, o conceito de comunicação terapêutica consiste na habilidade do profissional usar seu conhecimento sobre comunicação para ajudar a pessoa com tensão temporária a conviver com outras pessoas e ajustar-se ao que não pode ser mudado, e a superar os bloqueios à auto-realização para enfrentar seus problemas ${ }^{6}$.

Portanto, cabe ao enfermeiro desenvolver meios, instrumentos, técnicas, habilidades, capacidade e competência para oferecer ao paciente uma condição adequada de comunicação.

\subsection{A comunicação do traqueostomizado}

Quando submetidos às cirurgias de laringectomias parciais e totais, com a realização da traqueostomia, após a recuperação anestésica, a primeira constatação do paciente é a de que está afônico ou com afasia.

A traqueostomia é uma abertura cirúrgica efetuada na traquéia com a finalidade de favorecer a função respiratória, em situações de obstrução da via aérea superior, devido por exemplo a um tumor. Esta abertura é denominada estoma e nele é inserido uma cânula (um tubo) de polietileno ou metal, com ou sem balão. Em geral, as cânulas de polietileno com balão são usadas nas primeiras 72 horas pós-operatórias e, em seguida, é substituída pela cânula metálica. A cânula de polietileno sem balão é de alto custo e por isso não é freqüentemente utilizada nas instituições hospitalares governamentais. A cânula com balão impede a passagem do ar pelas cordas vocais, portanto, o paciente não consegue emitir o som laríngeo. A cânula metálica possibilita que o paciente emita sons (se as cordas vocais estiverem íntegras), porém nem sempre isso é possível nos primeiros dias após a cirurgia, devido ao edema da laringe. De qualquer modo, para falar com a cânula metálica, o paciente tem que obstruir a saída de ar, o que pode provocar dispnéia ${ }^{1,2,3}$.

A cânula de traqueostomia unidirecional permite a emissão de som, sem a necessidade de obstruir a saída de ar, porém, além de ser de alto custo, a manutenção da permeabilidade das vias aéreas é dificultada, sendo pois raramente utilizada ${ }^{2}$.

Para os pacientes laringectomizados totais, a traqueostomia é permanente. A reabilitação vocal é possível por meio da voz esofágica, prótese traqueoesofágica, laringe eletrônica ou voz bucal. Entretanto, esses meios são utilizados após algumas semanas de cirurgia, quando a cicatrização da ferida cirúrgica estiver adiantada e para esta reabilitação vocal requer muito tempo de treinamento.

Além da traqueostomia, nas laringectomias é freqüente o edema facial generalizado devido à ressecção ganglionar cervical, que impossibilita o paciente de movimentar os lábios e, portanto, a mímica labial também está prejudicada. Assim, a comunicação do paciente é realizada apenas por movimentos gestuais ${ }^{3}$.

Após 48 horas de pós-operatório, os sinais vitais do paciente restabelecem. A cognição e a sua necessidade de interagir com o meio ambiente acentuam-se. Neste momento, o paciente pode utilizar a comunicação através da escrita, dependendo da sua habilidade para tal. Entretanto, a utilização de caneta e papel têm desvantagens devido às características destes materiais e à dificuldade de utilização, devido a posição dorsal ou lateral do paciente no leito, a quebra do grafite, a necessidade de quantidade suficiente de papel e a de um suporte para o papel ${ }^{1,8,9}$.

Portanto, tanto nos casos de laringectomias parciais como totais, os pacientes necessitam de recursos para se comunicarem nos primeiros dias de pósoperatórios, sendo esse o foco do presente estudo.

SMELTZER \& $\mathrm{BARE}^{7}$ recomendam que um 
sistema inicial de comunicação deve ser implementado no pós-operatório mediato. Afirmam que "um quadro mágico é freqüentemente utilizado para a comunicação ou uma prancheta com papel e lápis... Se ele não é capaz de escrever, um quadro com figuras/palavras/frases ou sinais manuais pode ser utilizado" (p.412). As autoras salientam que os recursos utilizados podem deixar o paciente impaciente e enraivecido quando não é compreendido, desse modo a aplicação destes recursos deve ser realizado com atenção pela equipe de saúde.

BLACK \& JACOBS ${ }^{1}$ recomendam que "nos primeiros dias após a cirurgia, o paciente deve se comunicar pela escrita", acrescido dos gestos com a cabeça e das mãos. Afirmam que "o ato de evitar a conversação com o cliente, devido à dificuldade de comunicação, é humilhante, levando-o a se sentir frustado" (p. 970). Entretanto, a movimentação da cabeça será dificultada se o paciente tiver sido submetido à ressecção ganglionar cervical, comum nestas cirurgias. Quanto a movimentação dos membros superiores, dependerá do tipo e da localização da punção venosa.

Segundo BLONDIS \& JACKSON ${ }^{2}$, o paciente traqueostomizado não pode se comunicar nas primeiras 72 horas após o procedimento e isso leva à ansiedade $\mathrm{e}$ medo que podem acentuar, de forma negativa a freqüência respiratória e cardíaca, a cefaléia, náusea, vômito e anorexia. As autoras ainda afirmam que muitos pacientes traqueostomizados têm medo de não serem prontamente atendidos quando tiverem algum problema respiratório, e de nunca mais voltar a falar. Para as autoras, o uso de lápis e papel ou lousa mágica, como recursos temporários para a comunicação, podem reduzir esses sentimentos.

Assim, para os autores citados a lousa mágica, como um recurso para a comunicação verbal escrita do traqueostomizado, pode ser eficiente e tem custo acessível $^{1,2,3,7}$. Porém, esta afirmação não está respaldada em estudos científicos. Na literatura brasileira médica e de enfermagem, não encontramos nenhum estudo avaliando essa aplicação.

No estudo de $\mathrm{ZAGO}^{8}$, a pesquisadora tentou a utilização da lousa mágica com pacientes laringectomizados totais, mas esse recurso foi recusado pelos pacientes com as justificativas de que seria um brinquedo e pela inabilidade de usarem a escrita. A pesquisadora considerou, naquele momento, que essas justificativas estavam relacionadas com as características sócio-educacionais e culturais. Os informantes do seu estudo não tinham o primeiro grau de alfabetização completo, estavam na faixa etária acima de 50 anos e não tinham o hábito de escrever.

Com a mudança das características sócio econômico - educacionais dos pacientes laringectomizados, da instituição em foco, identificadas por MARTINEZ ${ }^{4}$, em 1966, propomos neste estudo a retomada da utilização deste recurso e a sua avaliação quanto à adequação e aceitação pelo paciente.

\section{METODOLOGIA}

O estudo foi desenvolvido nas enfermarias de Cirurgia de Cabeça e Pescoço de um hospital universitário, localizado na cidade de Ribeirão Preto-SP. Abrangeu pacientes internados que se submeteram aos procedimentos de laringectomia parcial ou total, ressutura de assoalho da boca e cordectomia, com realização da traqueostomia, maiores de 18 anos, conscientes, orientados e que sabiam escrever. Os pacientes foram contatados no dia da internação e consultados quanto à sua aquiescência em participar do estudo. Foram fornecidas informações sobre o estudo e os pacientes que concordaram em participar assinaram o termo de consentimento esclarecido. O estudo foi aprovado pelo Comitê de Ética da instituição.

Para o alcance do objetivo proposto, o estudo percorreu as seguintes etapas:

1. Aquisição das lousas mágicas para o desenvolvimento do estudo;

2. Elaboração de um instrumento abordando as características específicas da lousa como recurso para a comunicação escrita, tais como: tamanho, influência das cores, necessidade de apoio adicional, posicionamento no leito, colaboração da equipe de saúde na utilização e sua aceitação pelo paciente;

3. Fornecimento do recurso no $2^{\circ}$ dia de pós-operatório, com as explicações de utilização necessárias;

4. Aplicação do formulário de avaliação entre o $5^{\circ}$ e $6^{\circ}$ dia de pós-operatório;

5. Análise descritiva dos dados.

Inicialmente realizamos um levantamento do número de cirurgias realizadas nos anos de 1995 e 1996, nas enfermarias de Cirurgia de Cabeça e Pescoço da instituição. Identificamos que nesse período, o serviço realizou cerca de 22 laringectomias parciais e totais com traqueostomia, com uma média de 10 cirurgias por ano. Frente a estes dados, o GARPO - Laringectomizados adquiriu cerca de 15 lousas mágicas.

A lousa mágica é um brinquedo de plástico, de três cores: verde, amarelo e rosa fluorescente; com a forma retangular, medindo 22 centímetros de largura e 25 centímetros de comprimento. Foi a de menor tamanho encontrado no comércio, com um custo de $\mathrm{R} \$ 3,00$ cada.

O formulário de coleta de dados foi elaborado tendo como foco questões de mensuração da adequação e aceitação do recurso pelo paciente. Ele foi validado por dois profissionais experientes na área temática da comunicação e da assistência com o traqueostomizado. 
Foi realizado um pré-teste com 2 pacientes laringectomizados, sendo novamente reformulado (Anexo).

Participaram do estudo 15 pacientes traqueostomizados e a coleta de dados realizou-se no período de agosto/97 a junho/98.

Os dados foram analisados quanto a freqüência e o conteúdo das respostas, utilizando-se a estatística descritiva.

\section{RESULTADOS E DISCUSSÃO}

\section{A - Caracterização da população}

A Tabela 1 apresenta o tipo de cirurgia ao qual o paciente submeteu-se. A laringectomia total foi a de maior freqüência.

Tabela 1 - Tipo de cirurgia submetida pelos pacientes no período de agosto/97 a julho/98, em um hospital universitário da cidade de Ribeirão Preto - SP

\begin{tabular}{l|c|c}
\hline TIPO DE CIRURGIA & $\begin{array}{c}\text { N }^{\mathbf{D}} \text { DE } \\
\text { PACIENTES }\end{array}$ & $\begin{array}{c}\text { FREQÜÊNCLA } \\
(\%)\end{array}$ \\
\hline Laringectomia total & 8 & $54 \%$ \\
\hline Laringectomia parcial & 4 & $26 \%$ \\
\hline $\begin{array}{l}\text { Ressutura de assoalho } \\
\text { da boca }\end{array}$ & 1 & $6 \%$ \\
\hline Cordec tomia & 2 & $14 \%$ \\
\hline TOTAL & $\mathbf{1 5}$ & $\mathbf{1 0 0} \%$ \\
\hline
\end{tabular}

Dessa população, 11 pacientes haviam sido submetidos à ressecção ganglionar cervical, apresentavam edema facial e punção venosa. A pedido das pesquisadoras, a punção venosa dos participantes foi realizada no membro superior esquerdo, pois eles eram destros.

Quanto ao gênero dos participantes, a literatura aponta que o câncer de laringe é mais freqüente no sexo masculino ${ }^{2,3,4,9}$, o que também foi identificado no presente estudo em que $94 \%$ são do sexo masculino. Em relação à idade, $90 \%$ dos participantes estão na faixa etária de 55 anos de idade e o estado civil que prevalece é o de casados, em $66 \%$. As profissões dos participantes são: motoristas $20 \%$, pedreiros $20 \%$, aposentados $12 \%$, auxiliares de cozinha $6 \%$, comerciantes $6 \%$ e outros $36 \%$. Um dado importante para a utilização de um recurso para a comunicação escrita é o do grau de instrução. Cerca de $80 \%$ dos participantes cursaram o $1^{\circ}$ grau de escolaridade e apenas $40 \%$ deles o concluiu; apenas $7 \%$ tinham o $2^{\circ}$ grau completo.

Esses resultados correspondem aos encontrado por MARTINEZ 4 quanto às características sócio econômico-educacionais dos laringectomizados da especialidade.

Quanto à utilização da escrita como meio de comunicação, $73 \%$ referiram que gostavam de escrever, $27 \%$ responderam que não gostavam; $14 \%$ utilizavam a escrita como meio de comunicação no cotidiano e $86 \%$ não usavam a escrita com freqüência.

Essas características ressaltam que a escrita não é um meio de comunicação normalmente utilizado pelos pacientes. Acreditamos que a sua formação educacional e atuação profissional não favorecem nem exigem a necessidade deste tipo de comunicação.

\section{B - Adequação da lousa mágica}

Em relação ao tamanho da lousa mágica, 92\% dos pacientes a consideraram adequada.

A influência das cores vibrantes, $86 \%$ dos participantes referiram que as suas características não interferiram na sua utilização. Qualitativamente, os participantes justificaram que entendiam a finalidade do recurso, na situação em que estavam.

Quanto à facilidade do recurso para registrar a sua mensagem com agilidade, $86 \%$ consideram a lousa mágica como um instrumento que favoreceu uma comunicação escrita mais rápida e eficiente. Neste sentido, os participantes completaram que é preciso ser objetivo na hora de escrever a mensagem que se quer transmitir. Apenas um paciente não utilizou a lousa justificando que ela borra a escrita.

As características estruturais da lousa mágica foram bem aceitas pelos participantes: $86 \%$ consideramna firme o suficiente para a sua utilização no decúbito horizontal, não havendo necessidade de um outro apoio. Assim, a lousa mágica foi considerada pelos participantes como adequada no decúbito dorsal e sentado por $90 \%$ dos participantes.

$\mathrm{Na}$ comunicação escrita, o receptor deve ser paciente e esperar que o paciente (o mensageiro) escreva a mensagem por inteiro, pois, as interrupções e as tentativas de adivinhação pelo receptor podem provocar ansiedade no paciente $e^{1,2,3,9}$. Neste sentido, tivemos o cuidado de informar principalmente a equipe de saúde quanto a esta atenção. Desse modo, $86 \%$ dos participantes referiram que as pessoas com as quais se comunicaram mostraram-se interessadas e pacientes pela finalização da redação da mensagem.

Quanto ao fato do recurso ser um "brinquedo", não houve nenhuma rejeição pelos participantes, o que mostra que os participantes embora sejam adultos, de uma faixa etária avançada, souberam compreender a finalidade do recurso.

A Tabela 2 mostra que a lousa mágica foi 
aprovada como recurso que favorece a comunicação escrita com a equipe de saúde pelos pacientes.

Tabela 2 - Aprovação da utilização e continuidade do uso do recurso pelos pacientes de Cabeça e Pescoço, de um hospital universitário da cidade de Ribeirão Preto - SP, no período de agosto/97 a julho/98

\begin{tabular}{c|c|c}
\hline $\begin{array}{c}\text { APR OVAC̆ Ão } \\
\text { DO RECURSO }\end{array}$ & $\begin{array}{c}\text { APROVAÇ̃̃O DA } \\
\text { UTLIZAÇÃO }\end{array}$ & $\begin{array}{c}\text { APROVAÇ̃̃O DA SUA } \\
\text { CONTINUIDADE }\end{array}$ \\
\hline Sim & $96 \%$ & $96 \%$ \\
\hline Não & $4 \%$ & $4 \%$ \\
\hline TOTAL & $\mathbf{1 0 0} \%$ & $\mathbf{1 0 0 \%}$ \\
\hline
\end{tabular}

No instrumento, formulamos questões abertas de modo a obtermos outras informações e comentários sobre o recurso que não foram respondidas por 14 participantes. Um único paciente recomendou a lousa para todos os pacientes traqueostomizados justificando que Olha, eu não sei escrever direito e não gosto. Naquele dia que me deram a lousa, eu tive falta de ar, não podia chamar ninguém! Apertei a campainha, peguei a lousa que estava do meu lado, consegui escrever "ar". Quando a enfermeira chegou, ela leu e entendeu na hora! E resolveu o meu problema. Por isso, todo mundo tem que ter uma e vocês tem que... forçar mesmo a usar. No começo achei que ia ser bobagem. Mas não foi. As cores, olha, as cores verde e rosa... é um brinquedo..., na minha idade... é importante, é isso que importa, salva a gente. Eu vou levar para casa, vai me ajudar.

Um resultado quali e quantitativamente importante foi que dos 15 participantes, 14 solicitaram para que permanecessem com a lousa após a alta hospitalar. Referiram que a mesma poderia ser útil para a comunicação com a família, o que foi concedido. Dessa forma, não foi possível avaliarmos a duração do uso do recurso. Destacamos que, em média, o período de utilização do recurso na internação foi de 9 dias e, durante este período, a lousa mágica permaneceu com as mesmas características, permitindo a agilidade na redação das mensagens, em qualquer posição de decúbito, não requerendo outro tipo de apoio.

\section{CONCLUSÕES}

Este estudo permitiu concluir que:

- Quanto a adequação da lousa como recurso para a comunicação verbal escrita do traqueostomizado, $73 \%$ dos pacientes consideraram o recurso adequado e $86 \%$ dos pacientes informaram que a lousa favoreceu a comunicação com a equipe de saúde.

- Em relação a aceitação da lousa como recurso para a comunicação verbal escrita do traqueostomizado, a lousa teve a aceitação de $96 \%$ dos pacientes.

\section{CONSIDERAÇÕES FINAIS}

Frente à importância de um meio de comunicação para os traqueostomizados, no pós-operatório, para a sua integração no contexto hospitalar, é fundamental que busquemos por recursos eficientes e de baixo custo para a instituição, para suprir tal necessidade.

A literatura de enfermagem internacional aponta a lousa mágica como um recurso possível. Entretanto, pelo fato deste recurso ser um brinquedo e ter cores vibrantes preocupava-nos a sua aceitação entre pacientes brasileiros. Assim, buscamos neste estudo avaliar a adequação e a aceitação desse recurso pelos traqueostomizados.

Os resultados mostraram-nos que ele é adequado e aceito pelos pacientes; possibilita que seja utilizado em qualquer decúbito em que o paciente esteja. Porém, como limitações, requer que o paciente tenha a habilidade da escrita e que a equipe de saúde dê liberdade ao paciente para escrever, não interrompendo, mantendo a punção venosa no membro não utilizado para a escrita, e motivando-o para a sua utilização enquanto outros recursos não forem possíveis.

Julgamos que o seu custo não é alto para a instituição e frente à facilidade de utilização, aos resultados para o paciente e equipe de saúde, o seu uso é justificado.

Finalizando, contribuir para a adaptação da comunicação pós-operatória dos traqueostomizados é uma intervenção de enfermagem que demonstra a preocupação dos profissionais em desenvolver uma assistência qualificada.

\section{THE MAGIC BLACKBOARD IN THE PROMOTION OF WRITTEN COMMUNICATION BY TRACHEOSTOMIZED PATIENTS}

With the purpose of improving the communication of the tracheostomized patients, the present study was developed aiming at evaluating the acceptance of the magic blackboard as a resource for these patients's written communication. From the second day after the surgery, the blackboard was used by 15 tracheostomized patients. Subsequently, the authors applied an instrument to evaluate its acceptance. Results showed that $73 \%$ of the patients considered the resource appropriate for their conditions, $86 \%$ considered that it favoured the communication with the health team and the blackboard was accepted by $96 \%$ of 


\section{REFERÊNCIAS BIBLIOGRÁFICAS}

01. BLACK, J.M.; JACOBS, E.M. Luckman \& Sorensen : enfermagem médico - cirúrgica: uma abordagem psicofisiológica. 4. ed. Rio de Janeiro: Guanabara Koogan, 1996.

02. BLONDIS, M.N.; JACKSON, B.E. Nonverbal communication with patients: back to the human touch. 2. ed. New York: John Wiley, 1982.

03. CLARK, J.C.; McGEE, R.F. Enfermagem Oncológica. 2. ed. Porto Alegre: Artes Médicas, 1997.

04. MARTINEZ, E. L. Caracterização social dos pacientes internados nas enfermarias de cirurgia de Cabeça e Pescoço do Hospital das Clínicas da Faculdade de Medicina de Ribeirão Preto. Ribeirão Preto: Hospital das Clínicas da Faculdade de Medicina de Ribeirão Preto-USP, 1996. (Relatório Técnico do HCFMRP-USP, 1).
05. SILVA, M.J.P. Comunicação tem remédio: comunicação nas relações interpessoais em saúde. 2. ed. São Paulo: Gente, 1996.

06. STEFANELLI, M.C. Comunicação com paciente: teoria e ensino. 2. ed. São Paulo: Robe, 1993.

07. SMELTZER, S.C.O.; BARE, B.G. Brunner \& Suddarth: tratado de Enfermagem MédicoCirúrgica. 8. ed. Rio de Janeiro: Guanabara Koogan, 1998.

08. ZAGO, M.M.F. Plano de ensino para o preparo da alta médica do paciente laringectomizado. Ribeirão Preto, 1990. 145p. Dissertação (Mestrado) - Escola de Enfermagem de Ribeirão Preto, Universidade de São Paulo.

09 ZAGO, M.M.F.; SAWADA, N.O. Assistência multiprofissional na reabilitação da comunicação da pessoa laringectomizada. Revista da Escola de Enfermagem da USP, v. 32, n. 1, p. 67-72, 1998. 